\title{
Factors Influencing Implementation of Nursing Process by Nursing Students: A Qualitative Study
}

\author{
Tahere Moghadas (iD ${ }^{1}$ and Maryam Sedaghati Kesbakhi (iD) ${ }^{1,}$ \\ ${ }^{1}$ Department of Nursing, School of Medical Sciences, Tonekabon Branch, Islamic Azad University, Tonekabon, Iran \\ "Corresponding author: Department of Nursing, School of Medical Sciences, Tonekabon Branch, Islamic Azad University, Tonekabon, Iran. Email: \\ maryam.sedaghati77@gmail.com
}

Received 2020 November 01; Revised 2020 December 09; Accepted 2020 December 19.

\begin{abstract}
Background: The nursing process is a framework for nursing care. It is a systematic and dynamic method that can be used in all health care environments.

Objectives: We aimed to explore the factors that may influence the implementation of the nursing process by nursing students. Methods: A qualitative study was conducted through semi-structured face-to-face interviews. Fifteen nursing students were selected by purposive sampling. Inclusion criteria include sixth to eighth-semester nursing students who have experience of using the nursing process in clinical wards., The Graneheim and Lundman content analysis method was used to analyze the qualitative data.

Results: After analyzing the data, we created three main categories (awareness of the nursing process, individual-managerial factors, and the reflection of the nursing process).

Conclusions: Factors that influence the implementation of the nursing process by nursing students are varied. Therefore, nurse educators should remove barriers and provide facilities to promote the nursing process's implementation.
\end{abstract}

Keywords: Nursing Students, Nursing Process, Qualitative Research

\section{Background}

The nursing process is considered as the standard for nurses' work $(1,2)$. This is a systematic framework for evaluating patients' needs and solving nursing care problems $(3,4)$. Smeltzer et al. consider this standard to be the essence of nursing and believe that it is a thoughtful way to solve problems, meet patients' needs, and take care of them (5).

The nursing process is a mixture of cognitive, interpersonal, ethical, and legal skills (6). It involves interconnected steps that provide a systematic and motivational approach to patient care and lead to the organization and standardization of nursing services (7). Studies have shown that when nursing care is formed based on the nursing process, the quality of provided care and its impact increases, and services time shortens (8).

According to Ahmadi et al. report, nowadays, the routine of nursing care based on habit, repetition of nursing care, and lack of attention to the patient's need for caring are serious nursing problems. A common effort to replace the current nursing care practice with patient-centered practices and emphasize preserving the patient's integrity and unique needs by providing a proprietary nursing process is the consensus of all nursing experts (9).

Although numerous sources point to this approach's benefits and advantages and its training in nursing courses, it remains at the theory's level. Traditional nursing practices are still ongoing (10). Researchers and authors disagree on the nursing process's advantages and disadvantages $(11,12)$. While some researchers consider the nursing process a limitation on nurses' critical thinking, others believe it increases nurses' effective decisionmaking in different clinical settings. Several studies conducted in the United States and the United Kingdom reveal nurses' negative attitude towards nursing care plans based on the nursing process $(13,14)$. However, the nursing process can be implemented and adapted in each case, saving time and energy and preventing the occurrence or repetition of a mistake (15). Despite the benefits of using the nursing process and written care plans, there is still limited use of these tools (7).

The nursing process is a scientific and targeted method for solving the problem in providing care to clients, which is used dynamically and flexibly by nurses under different 
conditions $(6,16)$. Ghanbari quotes from Akbari that "according to available information and researches, this systematic approach is being implemented in a limited and inappropriate manner in Iran, evidence shows that, in addition to the lack of proper and complete implementation of the nursing process by nurses working in hospitals, the implementation of this care method for students and nursing educators working in higher education centers is also unknown" (17).

Clinical educators have a moderate awareness of the implementation of the nursing process (18), while a study revealed that implementing the nursing process to equip the students was ineffective, just a bureaucracy and a copy of the textbook to getting rid of special duties (19). One crucial problem in the nursing process teaching method is a failure to effectively equip the student with tools to use it in real-world conditions and perform professional tasks. Thus, applying effective teaching methods and enhancing students' active participation are necessary to apply the nursing process as a standard care method (20).

Nowadays, the nursing process is widely used in undergraduate nursing education in Iran. It provides care services, but the researchers' experience shows that nursing students are faced with many challenges in this regard. The non-implementation of the nursing process in clinical wards by nurses is probably one of the reasons. A few research has been conducted on the use of the nursing process and its implementation by nursing students. Certainly, the dimensions of this issue cannot be deeply examined by using quantities methods.

The authors had experience in the nursing process's clinical and theoretical education and observed the incomplete implementation of the nursing process or sometimes its non-implementation in clinical departments. Also, the corresponding author had a history of researching a qualitative way with content analysis methods. Due to the importance of this issue in nursing students, this research was conducted.

\section{Objectives}

We aimed to explore the factors that may influence the implementation of the nursing process by nursing students.

\section{Methods}

\subsection{Study Design}

This qualitative research was done using conventional content analysis.

\subsection{Participants}

In Iran, the nursing education program lasts four years, eight semesters. Subjects related to the nursing process starts from the first semester. From the second semester, students experience internships besides theory courses simultaneously, and the last two semesters are only clinical and internship courses.

By purposive sampling, 15 nursing students in the academic semester 6 to 8 were selected from two hospitals affiliated to the Islamic Azad Universities of Tonekabon Branch. Having experience using the nursing process in clinical wards was a requirement for the section.

\subsection{Data Collection}

Semi-structured interviews were conducted individually with 15 nursing students after obtaining informed written consent from each participant. Interviews were done in a quiet room of selected hospitals; the minimum and maximum time for these interviews were 20 and 50 minutes, respectively. The interview began with the following open question: What factors affect the implementation of the nursing process? What experience do you have in the implementation of the nursing process? All interviews were recorded with an MP3 player and then transcribed. Data were collected from February 2019 to June 2020. In general, the interviews lasted five months, and no interview repetition was required. Data collection continued up to data saturation. Eleven participants were interviewed, and after interviewing with participant number 12, no more new information was obtained. To test data saturation, three additional interviews were conducted.

\subsection{Data Analysis}

Data analysis was begun immediately after data collection. Interviews were recorded on the word-by-word by both researchers, and semantic units and primary codes were extracted from the texts. Content analysis with a conventional approach was used to analyze the data. Data analysis was carried out using a 5-step of Graneheim and Lundman method (21). For analysis, at first, "semantic units" were appeared from the participants' speeches, then the primary code was found. The data were carefully reviewed to extract the codes, and the relevant information was written in one place. Finally, identical codes were placed in one subcategory, and similar subcategories created the categories. In general, 728 primary codes were extracted in this study. In the process of analysis and continuous comparison, the number of primary codes decreased to 140 . The integration of these codes resulted in 10 subcategories, which were placed in 3 main categories. The data were analyzed by MAXQDA 10 Software. 
To assess the different study items, rigor was used four essential criteria, including credibility, conformability, dependability, and transferability (22). Regarding credibility, the researcher has been closely involved with participants and research data during the gathering, analyzing, and interpreting data for five months. Interview texts appeared codes, and subcategories were discussed and confirmed by five participants and seven university members. To obtain appropriate data, nursing students with more experience in the nursing process were chosen. Regarding conformability, the authors tried to complete the reports in detail, record them carefully, and preserve all the documents. To determine the dependability of the study, the research stages were independently studied by four qualitative researchers with a doctoral-level degree in nursing as external observers. Afterward, comparing these results showed similar consequences. Also, regarding transferability, the authors tried to describe the study's details, including the selection of participants, gathering data, and research stages for future research.

\section{Results}

Table 1 shows the characteristics of the participants. Based on data analysis, three main categories were obtained. The categories and subcategories have been shown in Table 2.

\begin{tabular}{cc}
\hline Table 1. Participants' Characteristics $(\mathrm{N}=15)$ & No. $(\%)$ \\
\hline Variable (Classification) & \\
\hline Age $(\mathrm{y})$ & $7(46.7)$ \\
$<22$ & $8(53.3)$ \\
\hline Gender 22 & \\
\hline Male & $5(33.3)$ \\
\hline Female & $10(66.7)$ \\
\hline Marital Status & \\
\hline Single & $14(93.3)$ \\
\hline Married & $1(6.7)$ \\
\hline Semester & \\
\hline 6 & $5(33.3)$ \\
\hline 7 & $4(26.7)$ \\
\hline Sum & $6(40)$ \\
\hline
\end{tabular}

The purpose of awareness of the nursing process stages is awareness of the staged assessment, nursing diagnosis, writing the purpose, prioritizing the goals, implementation, and evaluation. In this research, being aware of the

\begin{tabular}{l|l}
\hline \multicolumn{2}{l}{ Table 2. Categories, Subcategories } \\
\hline \multirow{4}{*}{ Categories } & \multicolumn{1}{c}{ Subcategories } \\
\hline \multirow{4}{*}{$\begin{array}{l}\text { Awareness of the process of } \\
\text { nursing }\end{array}$} & $\begin{array}{l}\text { Pay attention to the stage of } \\
\text { assessment }\end{array}$ \\
\cline { 2 - 2 } & Pay attention to nursing diagnosis \\
\cline { 2 - 2 } & $\begin{array}{l}\text { Pay attention to the purpose of } \\
\text { writing }\end{array}$ \\
\cline { 2 - 2 } & Pay attention to the evaluation \\
\hline \multirow{4}{*}{ Individual-managerial factors } & Individual student factors \\
\cline { 2 - 2 } & Individual patient factors \\
\cline { 2 - 2 } & Management factors \\
\hline \multirow{4}{*}{$\begin{array}{l}\text { The reflection of the nursing } \\
\text { process }\end{array}$} & Systematic work based on process \\
\cline { 2 - 2 } & Increasing creative thinking \\
\cline { 2 - 2 } & Duality in student satisfaction \\
\hline
\end{tabular}

nursing process stages and receiving adequate education in proper communication with the patient and physical examination were considered as factors influencing the implementation of the nursing process by nursing students. Below are some examples of quotes:

One of the participants about paying attention to the stage of assessment says: "In assessment, I am considering demographic information such as age, occupation, marital status, as well as the chief complain, current disease, history of the disease and hospitalization, history of major diseases in the family, history of drug use, social history, and food and medicine allergy" [P,13].

Another participant about paying attention to nursing diagnosis says: "At the time of writing the nursing diagnosis, attention to NANDA'S nursing diagnosis list is essential." $[\mathrm{P}, 14]$.

A participant about paying attention to the purpose of writing says: "Every nursing diagnosis has its own goal. The goal must have three features: conditions, criteria, and behavioral verb" [P, 15]. And another participant about paying attention to evaluation says: "In fact, at the evaluation stage, we examine the effectiveness of the training given to patients and their implementation by the patient" [P, 10].

The purpose of the student's individual factors is his experience and attitude toward writing the nursing process. Individual factors include participation and cooperation with the student, student confidence, academic and financial status, and physical and emotional condition. For example, "Patient cooperation, patient's better physical condition, impatience, inability to speak, fatigue, and pain can be effective on the implementation of the nursing process" $[\mathrm{P}, 12]$.

In the case of management factors, the following issues were raised: Limitations on nursing duties, lack of facili- 
ties, lack of faculty members' attention to the nursing process, high number of patients, lack of personnel's attention to the student, lack of cooperation with the student, spending a lot of time to the process implementation, lack of access to the patient records in the morning, crowded ward, lack of suitable place for interviewing, barring head nurse for physical examination by student, inconsistency in nurse and student work, requiring physician's order for some actions, work compression, not being legal of nursing process in hospital by personnel, proposal for holding nursing process workshops, performing nursing care based on division of labor, attention of the internship professor to the importance of the process, encouraging internship professor to write the process, continuing the practical training of the process in the training environment following the theory training, encouraging students on the excellent nursing process, holding communication skills courses, providing classes and courses for recalling the nursing process, solving the executive problems of the nursing process. In the following, there is a quotation for this case: "The attention of the trainee teacher to the correct writing of the nursing process by the students, the provision of educational classes about the nursing process before the onset of internship, the practical training of writing the nursing process in the training environment, the provision of the necessary facilities and the necessary cooperation between the departmental staff and the students to implement the nursing process can be very effective"[P, 8].

Regarding the systematic work based on the process which was raised, some cases such as guiding the nursing process, having a specific framework, doing the work in principle, doing things based on consecutive and orderly steps. For example, "The nursing process is better than a routine method because the nursing process acts like a guide and directs our work" [P, 7].

Following, there is a quotation about increasing creative thinking: "I think the nursing process improves creative thinking because the student thinks for action and finding solutions to problems, tries combining previous actions and a new solution" $[\mathrm{P}, 4]$.

In the case of duality in student satisfaction, the following issues were raised: Satisfaction due to increased hope in student, the sake of feeling useful and effective, preventing repetitive work, improving quality of work, and time savings, satisfaction increase due to increased self-esteem, seeing the outcome of the work and observing the change of the patient's condition and patient tracking capability, dissatisfaction due to the ineffective actions, lack of patient collaboration, lack of personnel cooperation, lack of proper and adequate training, lack of supervision on activities. Accordingly, one of the participants says: "In my opin- ion, the satisfaction or dissatisfaction of the nursing process depends on the student himself or herself; if the students are not interested in doing the nursing process and don't know the importance of this action, they consider doing it bases on the nursing process as a futile activity which is a wasting time " $[P, 8]$.

\section{Discussion}

In this research, one of the factors influencing nursing process implementation is to be aware of the nursing process steps and have adequate knowledge and training in this field. Inadequate knowledge and education prevent the proper implementation of the nursing process. This lack of awareness is because of inappropriate education of the process at the nursing faculties and the lack of appropriate training and practice on the scientific use of the nursing process in patient care. These findings are consistent with the results obtained from three similar studies (23-25).

In a study on 68 faculty members and senior nursing students, it was concluded that $89.5 \%$ of faculty members considered a lack of knowledge of the concept of the nursing process as an individual's barrier to the implementation of the nursing process (26). A study showed that most nurses lacked sufficient knowledge and skills in implementing nursing processes (27). However, many of the overseas studies reveal contradictions with studies in Iran. A study in Egypt showed that nurses' knowledge in the nursing process was excellent, and many nurses have shown confidence in implementing nursing processes (28). Other studies reported that nurses' theoretical knowledge about implementing the nursing process steps and their competence in implementing this knowledge is excellent (29). Since the nursing process is a systematic, ongoing, and dynamic program and acts as a chain connected, cutting off part of this chain or failure to perform part of it leads to complete disruption. In this regard, Castledine writes that the nursing process is continuously cyclical, helping nurses follow the patient's recovery stage (30).

In this study, management factors are mentioned as factors influencing the implementation of the nursing process; In two studies, management barriers from nurses perspectives were a shortage of nursing staff, not having enough time to implement the nursing process, excessive demands, and lack of preparedness for implementation of the nursing process, not paying attention to the interest of nurses in choosing their workplace, lack of follow up and monitoring, and the insufficient number of trained nurses in the nursing process $(31,32)$ 
In the present study, another factor affecting the implementation of the nursing process is individual factors; Others also emphasized that individual characteristics such as lack of sufficient enthusiasm in using the nursing process, resistance to change, professional development and advancement, and no belief in applying the patient care impact implementation of the nursing process (32). Interest, motivation, belief, and attitude are also essential for the implementation of the nursing process. Whatever nursing students' attitudes towards the nursing process are positive, their attitudes towards doing the nursing process will be higher (31).

Our study also emphasized systematic work based on the nursing process to improve its implementation. In one study, the results revealed that no format for writing was one of the factors affecting the implementation of the nursing process (31).

\subsection{Conclusions}

According to the study findings, an essential nursing process barrier is a lack of nursing staff, so that nurses do not have enough time to use and implement this systematic approach. The disbelief of hospital officials in the nursing process and the lack of support for its use are also considered management barriers, which can be due to their lack of awareness about the importance and impact of this method in improving patient outcomes and enhancing the health care quality (20).

Nursing students should be accustomed to all the nursing process concepts and steps and intimate with them to efficiently use the nursing process in different clinical situations and their application. Therefore, it is necessary that the nursing process's theoretical and practical training be taught to students from the first year of study in the college, and it should be continued throughout the study pe$\operatorname{riod}(33)$.

Nursing education planners at the ministry level, heads of medical universities, and nursing schools whose main goals are health promotion, improvement of patients' condition, saving on health care costs, and preventing long-term hospitalization of patients can benefit from the findings of this research.

\section{Footnotes}

Authors' Contribution: The manuscript is an original work, and all data, tables, etc., used in this manuscript are prepared originally by the authors. MSK and TM designed the study. The data were collected, analyzed, and interpreted by MSK and TM. Both authors contributed toward drafting, revising, and approved the final manuscript
Conflict of Interests: There is no conflict of interest to disclose.

Ethical Approval: The required permissions were obtained from all of the Research Deputy of the Islamic Azad University of Tonekabon Branch. The study was approved by the Azad University of Tonekabon Branch under Ethical Code No. IR. IAU.TON. REC.1397.023. All necessary permissions were obtained from the Islamic Azad University, Tonekabon branch.

Funding/Support: This research did not receive any specific grant from funding agencies in the public, commercial, or not-for-profit sectors.

Informed Consent: Participants' verbal and written informed consent was taken from the nursing students before data collection. Besides, nursing students were assured of the confidentiality of the data and voluntary participation in the study.

\section{References}

1. Timby B. Fundamental nursing skills and concepts. 9 th ed. Philadelphia: Lippincott Williams and Wilkins; 2008.

2. Amante LN, Anders JC, Meirelles BH, Padilha MI, Kletemberg DF. The interface between teaching of the nursing process and the application in professional practice. Revista Eletrônica de Enfermagem. 2010;12(1). doi: 10.5216/ree.v12i1.9538.

3. Huckabay LM. Clinical reasoned judgment and the nursing process. Nurs Forum. 2009;44(2):72-8. doi: 10.1111/j.1744-6198.2009.00130.x.

4. Craven R, Hirnle C. Fundamentals of nursing: Human health and function. 6th ed. Philadelphia: Lippincott Williams \& Wilkins; 2009.

5. Smeltzer S, Bare B, Hinkle J, Cheever K. Brunner \& Suddarth's textbook of medical-surgical nursing. 12th ed. Philadelphia: Lippincott, Williams and Wilkins Co; 2010.

6. Taylor C, Lillis C, Lemone P, Lynn P. Fundamentals of nursing, the art and science of nursing care. 7th ed. Philadelphia: Lippincott Williams and Wilkins; 2010.

7. Agyeman-Yeboah J, Korsah KA, Okrah J. Factors that influence the clinical utilization of the nursing process at a hospital in Accra, Ghana. BMC Nurs. 2017;16:30. doi: 10.1186/s12912-017-0228-0. [PubMed: 28615989]. [PubMed Central: PMC5466728].

8. Akbari Kaji M, Farmahani Farahani B. [The effect of nursing process education on nursing care quality of schizophrenic patients].J Kashan Univers Med Sci (FEYZ). 2011;15(1):32-7. Persian.

9. Ahmadi F, Nobahar M, Alhani F, Falahi Khoshknab M. [Perspectives of retired nurses on factors that affect quality of nursing care]. Hayat. 2011;17(1):14-34. Persian.

10. Wongs D. Textbook of Pediatric Nursing. 9th ed. US: W B Saunders Co; 2013.

11. Creasia J, Parker B. Analysis and evaluation of contemporary nursing knowledge. nursing models and theories. Philadelphia: F.A.Davis Co; 2007.

12. Wilkinson J. Nursing process \& critical thinking. 5th ed. Boston: Pearson; 2011.

13. Ramos LAR, Carvalho ECD, Canini SRMDS. Opinion of nursing aids and nursing technicians about the nursing process. Revista Eletrônica de Enfermagem. 2009;11(1):39-44. doi:10.5216/ree.v11.46863.

14. Creasia J, Friberg E. Conceptual foundation; the bridge to professional nursing practice. 5th ed. St Louis: Mosby Elsevier Co; 2011. 
15. Hayrinen K, Lammintakanen J, Saranto K. Evaluation of electronic nursing documentation-nursing process model and standardized terminologies as keys to visible and transparent nursing. Int $J$ Med Inform. 2010;79(8):554-64. doi: 10.1016/j.ijmedinf.2010.05.002. [PubMed: 20617569].

16. Potter P, Perry A, Stockert P, Hall A. Essentials for nursing practice. 8th ed. Philadelphia: Mosby Elsevier; 2015.

17. Ghanbari A, Monfared A, Hoseinzadeh T, Moaddab F, Sedighi A. The impact of the nursing process education on critical thinking of nursing students. Res Med Edu. 2017;9(2):25-33. doi: 10.29252/rme.9.2.33.

18. Oshvandi K, pourYousef S, Bikmoradi A, Yousefzadeh M. [The effects of inquiry- based clinical instruction of nursing students on applying nursing process skill]. Sci J Hamedan Nurs \& Midwifery faculty. 2013;21(1):5-14. Persian.

19. Heidari H, Mardani Hamooleh M. Nursing students' experiences regarding nursing process: A qualitative study. Res Dev Med Edu. 2016;5(2):101-4. doi:10.15171/rdme.2016.021.

20. Akbari M, Shamsi A. A survey on nursing process barriers from the nurses view of intensive care units. J Crit Care Nurse. 2011;3:181-6.

21. Graneheim UH, Lundman B. Qualitative content analysis in nursing research: concepts, procedures and measures to achieve trustworthiness. Nurse Educ Today. 2004;24(2):105-12. doi: 10.1016/j.nedt.2003.10.001. [PubMed:14769454].

22. Guba E. Criteria for assessing the trustworthiness of naturalistic. Educ Thecnolo Res\& Dev. 1981;29(2):75-91.

23. Akbari M. The effect of nursing process education to nurses on quality of nursing cares [dissertation]. Tehran: Islamic Azad Univ; 2009.

24. Rajabpoor M, Zarifnejad GH, Mohsenizadeh SM, Mazloum SR, Pourg haznein T, Mashmoul A, et al. Barriers to the implementation of nursing process from the viewpoint of faculty members, nursing managers, nurses, and nursing students. J Holist Nurs Midwifery.
2018;28(2):137-42. doi: 10.29252/hnmj.28.2.137.

25. Atnafe G, Tadessa B, Habte N, Negesa L. The practice of nursing process and associated factors among nurses working in public hospitals of harari people national regional state, eastern ethiopia: A cross sectional study. J Med, Physiolog \& Biophysic. 2017;32:18-27.

26. Ghaforifard M, Haririan H, Aghajanlo A, Akbari M, Shirvani Y. [Barriers to the use of the nursing process from the perspective of Professors and students of the Zanjan Nursing School]. J Med Educ Devel. 2012;5(8):69-77. Persian.

27. Silva EG, de Oliveira VC, Neves GB, Guimaraes TM. [Nurses' knowledge about Nursing Care Systematization: from theory to practice]. Rev Esc Enferm USP. 2011;45(6):1380-6. doi: 10.1590/s008062342011000600015. [PubMed: 22241196].

28. Mahmoud M, Bayoumy H. Barriers and Facilitators for Execution of Nursing Process From Nurse' Perspective. Int J Adv Res. 1014;2(2):30015.

29. Queiroz O, Sant'Ana R, Oliveira S, Moinhos A, Santos L. Nurse's perception in front of the implementation of nursing diagnosis and prescription. J Nurs UFPE on line. 2012;6(7):1347-51.

30. Castledine G. Updating the nursing process. Br J Nurs. 2011;20(2):131. doi: 10.12968/bjon.2011.20.2.131. [PubMed: 21278665].

31. Mohammadi M, Ghafori F, Esmaeilivand M. [Assessing the Barriers Nursing Process by Nurses and Nurse managers in Surgical Wards in Imam Reza Hospital]. Kermanshah Nurs Res. 2015;11(3):57-65. Persian.

32. Abdelkader FA, Othman WN. Factors affecting implementation of nursing process: Nurses' perspective. IOSR-JNHS. 2017;6(3):76-82. doi: 10.9790/1959-0603017682.

33. Junttila K, Salantera S, Hupli M. Perioperative nurses' attitudes toward the use of nursing diagnoses in documentation. J Adv Nurs. 2005;52(3):271-80. doi: 10.1111/j.1365-2648.2005.03586.x. [PubMed: 16194180]. 